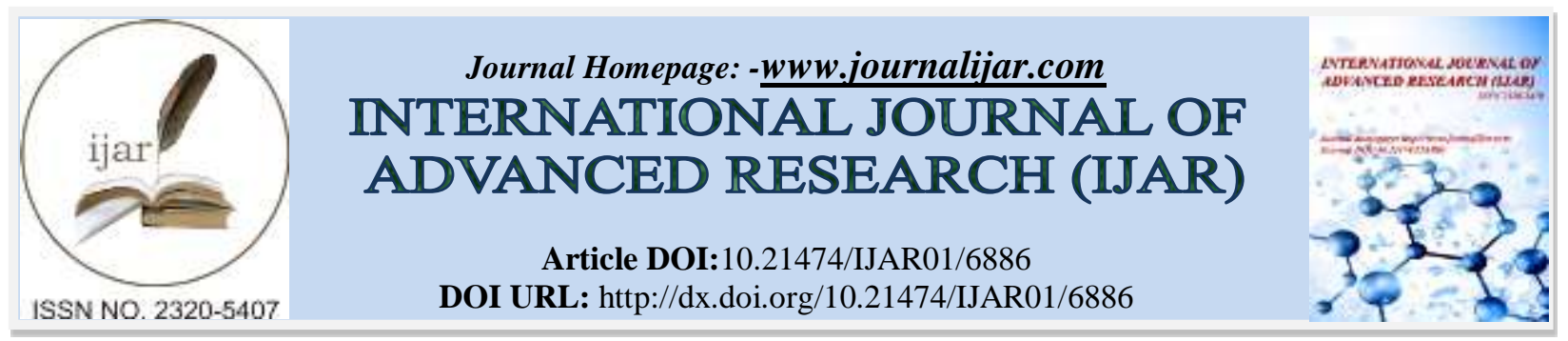

RESEARCH ARTICLE

\title{
ALUMINUM TOXICITY VS SALICYLIC ACID EFFECTS IN PEARL MILLET METHYLOME.
}

\author{
Baba Ngom ${ }^{1}$, Edward Mamati ${ }^{2}$, Ibrahima Sarr ${ }^{3}$ and Josphert Kimatu ${ }^{4}$. \\ 1. Pan African University Institute of basic Sciences, Technology and Innovation, department of Molecular \\ Biology and Biotechnology, PO Box 62000-00200 Nairobi, Kenya. \\ 2. Jomo Kenyatta University of Agriculture and Technology, Department of Horticulture, PO Box 62000-00200 \\ Nairobi, Kenya. \\ 3. Institut Sénégalais de Recherches Agricoles, CNRA, P.O Box 57, Bambey, Sénégal. \\ 4. South Eastern Kenya University, Department of Biology, P.O. Box 170- 90200, Kitui, Kenya.
}

\section{Manuscript Info}

\section{Manuscript History}

Received: 08 February 2018

Final Accepted: 10 March 2018

Published: April 2018

Keywords:-

DNA methylation; aluminum toxicity; salicylic acid; MSAP epigenotyping; Pearl millet

\begin{abstract}
Aluminum toxicity is one of most distributed plant abiotic stress in the world, causing root inhibition and therefore crop losses. Plants continuously adapt its defense to abiotic stresses through different mechanisms including DNA methylation. The methylome variation is influenced by external cues from environment or by hormonal signals. Salicylic acid is one of the most important hormones in plants, directing growth and defense. Its application is seen having the capacity to elicit plant defense mechanisms. In this study, the effects of aluminum toxicity and salicylic acid on DNA methylation were carried out in pearl millet using MSAP epigenotyping and ELISA test. The methylation analysis revealed aluminum treatment increased the global and CCGG methylation level whereas application of salicylic acid had reverse effects. Moreover, most of the methylation or demethylation due respectively to aluminum and salicylic acid, occurred at the external cytosine. This finding reveals that salicylic acid could overcome the negative effects of aluminum toxicity through DNA demethylation pathways.
\end{abstract}

Copy Right, IJAR, 2018,. All rights reserved.

\section{Introduction:-}

Aluminum (Al) is the most abundant metal in the earth's crust, comprising about $7 \%$ of its mass. They are widely distributed in tropical and subtropical regions, constituting approximately $30 \%$ of the total area of the planet and $50 \%$ of the arable lands in the world, as well as providing between 25 and $80 \%$ of vegetable production (Sade et al., 2016). It becomes phytotoxic when the soil $\mathrm{pH}$ drops below 4 and therefore limits plant production by reducing root growth (Kopittke et al., 2015). The root apex including root cap, meristem, and elongation zone, accumulates more $\mathrm{Al}$ and attracts greater physical damage than the mature root tissues (Bennet \& Breen, 1991; Ryan et al., 1993). It is implicated in oxidative stress (Zheng \& Yang, 2005), and has effects on cell wall, plasma membrane and nutrient unbalances (Schmohl \& Horst, 2000), induction of callose (Budikova \& Durcekova, 2004), and disturbance of cytoplasmic $\mathrm{Ca}^{2+}$ homeostasis (Rengel \& Zhang, 2003). Additionally, Al toxicity mostly affects the plasma membrane $\mathrm{H}^{+}$-ATPase by downregulating its expression (Shen et al., 2005; Chen et al., 2013; Guo et al., 2013; Zhang et al., 2017). 
However, although A1 toxicity has been identified as a problem of acid soils for over 70 years, its effects on epigenetic regulations, especially genomic methylation, remain largely speculative. Auxin, important hormone of root growth is seen as the activator of the plasma membrane $\mathrm{H}^{+}$-ATPase by phosphorylation during hypocotyl elongation in Arabidopsis (Takahashi et al., 2012). Recent study suggested that auxin could be influenced by a salicylic acid-repressing pathway through DNA demethylation mechanism at seedling development (Ngom et al., 2017). Furthermore, application of aluminum increased the methylated loci in Zea mays seedlings (Taspinar et al., 2018), whereas application of salicylic acid on Pennisetum glaucum seedlings caused DNA demethylation (Ngom et al., 2017).

In this study, the effects of aluminum toxicity and salicylic acid were carried on pearl millet (P. glaucum) methylome using methylation-sensitive amplified polymorphism epigenotyping.

\section{Materials and methods:- \\ Plant materials:-}

Four genotypes of pearl millet were used in the study: Souna 3 (PMS3), IBV 8004 (PMI8), Gawane (PMG), and Thialack 2 (PMT2). These are early-flowering photosensitive varieties with a growth cycle of 85-95 days. The seeds were obtained from the Senegalese Agricultural Research Institute of Bambey (Senegal). Seeds were disinfected using $1 \%$ of calcium hypochlorite $\mathrm{Ca}(\mathrm{ClO})_{2}$ for $10 \mathrm{~min}$ and then washed five times with sterile deionized water to remove any remaining chlorine.

\section{Plant growth conditions:-}

Murashige and Skoog was used as a medium to sow the pearl millet seeds. The media were supplemented with $0.5 \mathrm{mM}$ of salicylic acid and $400 \mu \mathrm{M}$ of aluminum (Table 1). After preparation, the media $\mathrm{pH}$ was adjusted to 4 and autoclaved with $121^{\circ} \mathrm{C}$ for $20 \mathrm{~min}$. After autoclaving, the media were cooled down in room temperature during $48 \mathrm{hrs}$ to check any traces of contamination. The contaminated media were discarded.

Table 1:-Combined treatments of aluminum and salicylic acid

\begin{tabular}{|l|l|l|l|}
\hline \multirow{2}{*}{} & \multicolumn{2}{|l|}{ Aluminum and salicylic acid applications } & Al+SA \\
\cline { 2 - 4 } & Control & Al & $400 \mu \mathrm{M}$ \\
\hline Aluminum chloride & $0 \mu \mathrm{M}$ & $400 \mu \mathrm{M}$ & $0.5 \mathrm{mM}$ \\
\hline Salicylic acid & $0 \mathrm{mM}$ & $0 \mathrm{mM}$ & \\
\hline
\end{tabular}

15 seeds were sown per medium and for each treatment with three replicates. The seeds were incubated in darkness for $48 \mathrm{hrs}$. The germinated seedlings were kept in a growth chamber set at $8 \mathrm{hrs}$. of darkness and a 16 hrs. of light and a temperature of $25^{\circ} \mathrm{C}$ during ten days of development for methylation analysis.

\section{MSAP epigenotyping:-}

The DNA from roots were extracted using ZR plant/seed DNA minipreps (Cat No. D6020) following the company extraction. The eluted DNA was subjected to genomic DNA methylation analysis. The extracted DNA was subjected to a Methylation-Sensitive Amplified Polymorphism (MSAP) analysis using two isoschizomers MspI and HpaII targeting the CCGG motifs, and EcoRI targeting GAATTC sites (Al-Lawati et al., 2016). This method is based primarily on Amplified Fragments Length Polymorphism (AFLP) analysis. It uses two different reactions with MspI/EcoRI, and HpaII/EcoRI. The isoschizomers recognize the same DNA site 5'-CCGG-3' with different sensitivity to methylation (Table 2).

Table 2:- Sensitivity of the isoschizomers HpaII and MspI to methylation of CCGG sites

\begin{tabular}{|c|c|l|c|}
\hline HpaII pattern & MspI pattern & Epigenetic status & Motifs \\
\hline 1 & 1 & Unmethylation & CCGG \\
\hline 1 & 0 & Methylation of external cytosine & mCCGG \\
\hline 0 & 1 & Methylation of internal cytosine & CmCGG \\
\hline 0 & 0 & Mutation/Non-target & - \\
\hline
\end{tabular}


$100 \mathrm{ng}$ DNA samples were digested with NEB EcoRI-10 U at $37^{\circ} \mathrm{C}$ for $2 \mathrm{hrs}$, , before deactivation by heating at $65^{\circ} \mathrm{C}$ for $20 \mathrm{~min}$. Then, the digested DNA fragments were subjected to NEB HpaII-10 U and NEB MspI-10 U digestion into two separated series at $37^{\circ} \mathrm{C}$ overnight. The restriction enzymes were deactivated by heating at $80^{\circ} \mathrm{C}$ for 15 min. Then, each MSAP series was subjected to ligation reactions (NEB T4 DNA ligase-10 U) with EcoRI adaptors $(10 \mathrm{mM})$ and $\mathrm{MspI} / \mathrm{HpaII}$ adaptor $(10 \mathrm{mM})$ (Table 3). The ligation mix was incubated overnight at room temperature. Pre-selective amplification was performed in a $50 \mathrm{~mL}$ reaction volume with EcoRI primer (10 mM), and MspI/HpaII primer (10 mM) (Table 3), diluted restriction-ligation DNA and One Taq standard buffer.

The pre-selective amplification was realized with the following temperature cycling conditions: one cycle at $94 \mathrm{C}$ for $30 \mathrm{~s} ; 30$ cycles at $94 \mathrm{C}$ for $30 \mathrm{~s}, 51 \mathrm{C}$ for $30 \mathrm{~s}$, and $72 \mathrm{C}$ for $60 \mathrm{~s}$, and finally one cycle at $72 \mathrm{C}$ for $2 \mathrm{~min}$. A $10-\mathrm{mL}$ aliquot of the pre-selective amplification products was run on a $1.5 \%$ agarose gel with a $1 \mathrm{~kb}$ DNA ladder to validate the pre-amplification step. Finally, a second amplification was done by selectively amplifying methylated DNA fragments using different primer combinations (Table 3) to generate an MSAP fingerprint. The PCR conditions were as follows: $94^{\circ} \mathrm{C}$ for $30 \mathrm{~s}, 12$ cycles at $94^{\circ} \mathrm{C}$ for $30 \mathrm{~s}, 65^{\circ} \mathrm{C}$ for $30 \mathrm{~s}$, and $72^{\circ} \mathrm{C}$ for $60 \mathrm{~s}, 23$ cycles at $94^{\circ} \mathrm{C}$ for $30 \mathrm{~s}$, $51^{\circ} \mathrm{C}$ for $30 \mathrm{~s}$ and $72{ }^{\circ} \mathrm{C}$ for $60 \mathrm{~s}$, and finally one cycle at $72^{\circ} \mathrm{C}$ for $60 \mathrm{~s}$. The PCR products were then run on a gel, and the MSAP profile was used for data scoring.

Table 3:-Primers and adaptors of MSAP epigenotyping

\begin{tabular}{|c|c|c|}
\hline Epigenotyping steps & Adaptors and Primers & Sequences (5'-3') \\
\hline \multirow[t]{3}{*}{ Ligation } & \multirow[t]{2}{*}{ EcoRI adaptors } & CTCGTAGACTGCGTACC \\
\hline & & AATTGGTACGCAGTCTAC \\
\hline & MspI/HpaII adaptor & CGAGCAGGACTCATGA \\
\hline \multirow[t]{2}{*}{ Pre-selective amplification } & EcoRI primer & GACTGCGTACCAATTC \\
\hline & MspI/HpaII primer & ATCATGAGTCCTGCTCGG \\
\hline \multirow[t]{6}{*}{ Selective amplification } & \multirow[t]{4}{*}{ EcoRI selective primers } & GACTGCGTACCAATTC-AAC \\
\hline & & GACTGCGTACCAATTC-ACC \\
\hline & & GACTGCGTACCAATTC-ACA \\
\hline & & GACTGCGTACCAATTC-AAG \\
\hline & MspI selective primer & ATCATGAGTCCTGCTCGGTCCA \\
\hline & HpaII selective primer & ATCATGAGTCCTGCTCGGTCAA \\
\hline
\end{tabular}

The MSAP profile was then transformed into a binary matrix, with 1 as a presence of loci and 0 the absence of loci (Table 2). Only 50-bp or longer PCR products were considered for analysis. The internal cytosine methylation and the external cytosine methylation (hemimethylation) were considered in this study. The absence of both bands $(0,0)$ is considered as mutation or non-target regions.

The raw data from the MSAP profile were analyzed using RMSAP 1.1 .8 for classification of methylationsusceptible locus or non-methylated locus. The outputs generated by the software were the percentage of methylated and unmethylated fragments and the types of methylation (Perez-Figueroa, 2013).

\section{Global methylation estimation:-}

To estimate the relative global cytosine DNA methylation, the enzyme-linked immunosorbent assay technique using an Imprint ${ }^{\circledR}$ Methylated DNA Quantification Kit (MDQ1, Sigma) was used with equal amount of DNA (100ng) following the company instructions.

Nei epigenetic distance:-

Following aluminum and salicylic acid treatments, the Nei genetic distance was determined using DNA methylation data and GenAlex version 6.5 (Peakall \& Smouse, 2012) for all pearl millet varieties. 


\section{Statistical analysis:-}

All statistical analysis was performed using R 3.2.5. Each data set was tested for normality and homogeneity of the variance. The data was analyzed using ANOVA to compare methylation level difference and LSD for mean separation.

\section{Results:-}

\section{CCGG DNA methylation level:-}

The methylation analysis was carried following aluminum and salicylic acid treatments. The results showed a significant difference between the treatments for all varieties $(\mathrm{P}<0.05)$. The control plants (without aluminum and salicylic acid) had lowest methylation level with plants treated with combined aluminum and salicylic acid. The highest methylation level was found during aluminum treatment while adding of salicylic acid diminished it (Figure $1)$.
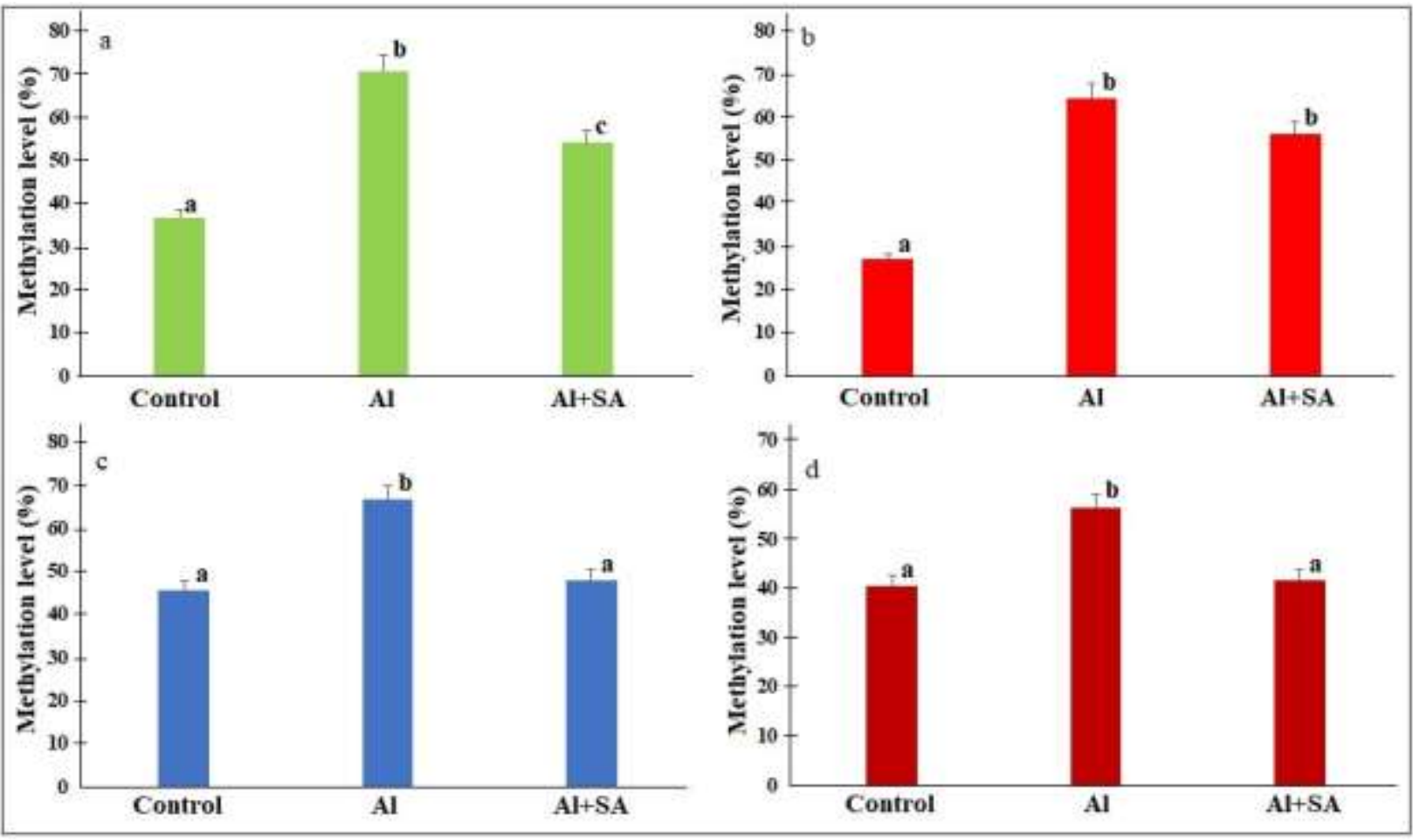

Figure 1:- Methylation level after aluminum and salicylic acid treatments. Highest methylation level found during aluminum application. Al: aluminum, SA: salicylic acid, control: without SA and Al. CCGG: non-methylation, mCCGG: hemimethylation, CmCGG: internal cytosine methylation. a: PMS3; b: PMG; c: PMI8; d: PMT2

\section{CCGG methylation mapping:-}

The type and the occurrence of methylation have been determined. The percentage of unmethylated cytosine (CCGG) was very low in all varieties without aluminum and salicylic acid treatments (controls). However, it increased with aluminum and salicylic acid applications. Furthermore, most of the methylation occurred at the external cytosine while the level of methylation was low at the internal cytosine. The hemimethylation was higher during aluminum treatment and decreased a bit after combination of aluminum and salicylic acid (Figure 2). 


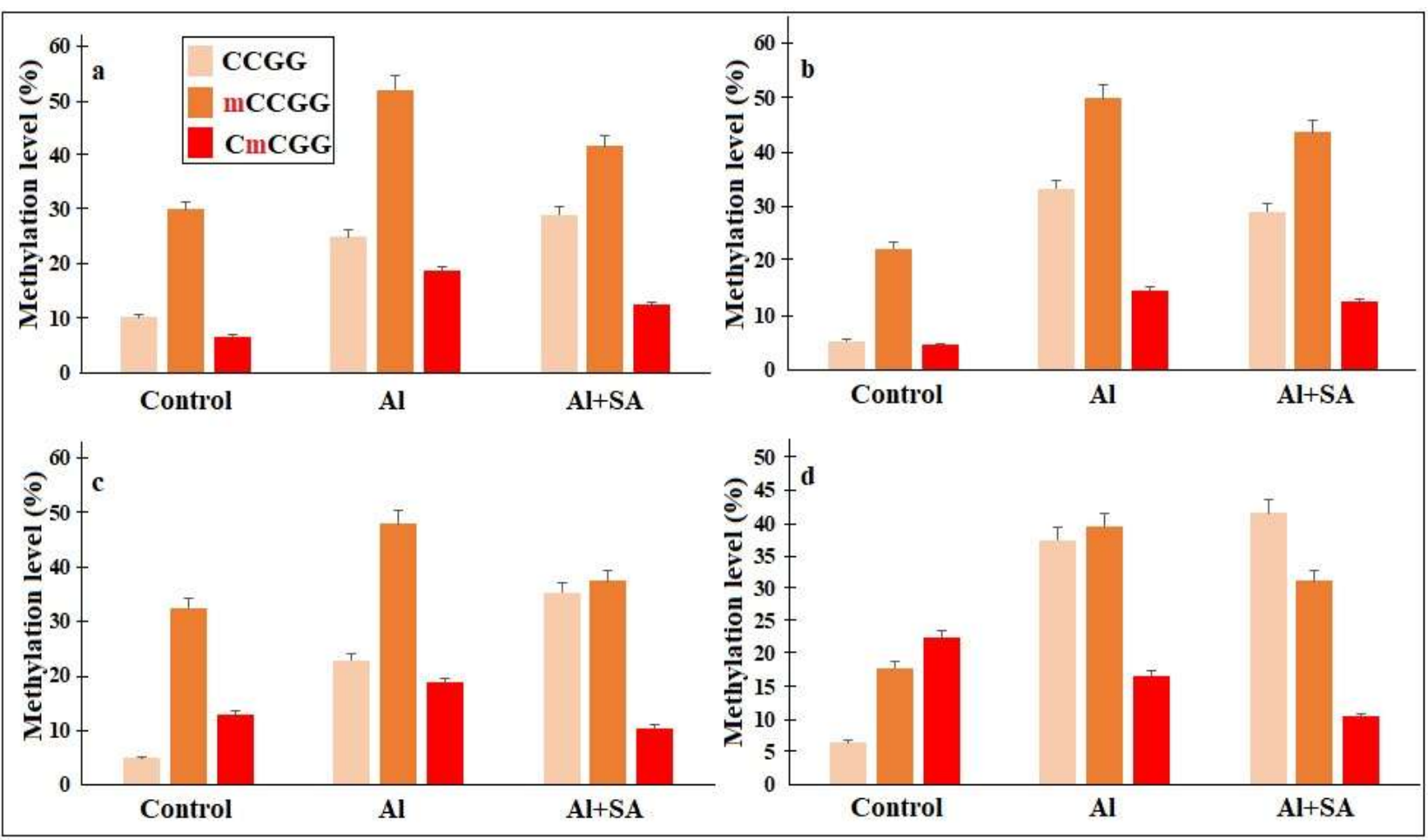

Figure 2:-Types and occurrence of methylation following aluminum and salicylic acid applications. Most of the methylation occurred at external cytosine. Four varieties: a PMS3, b PMG, c PMI8, and d PMT2. Al: aluminum, SA: salicylic acid, control: without Al and SA. CCGG: non-methylation, mCCGG: external cytosine methylation (hemimethylation), and CmCGG: internal cytosine methylation

\section{Global Cytosine DNA methylation:-}

The global cytosine DNA methylation was measured after salicylic acid and aluminum application during seedling development. The results showed that aluminum treatment increased the global DNA methylation for all varieties compared to the controls. However, the combination aluminum-salicylic acid decreased the level of DNA methylation even though the changes depended on the variety, PMG being less sensitive to salicylic acid (Figure 3).

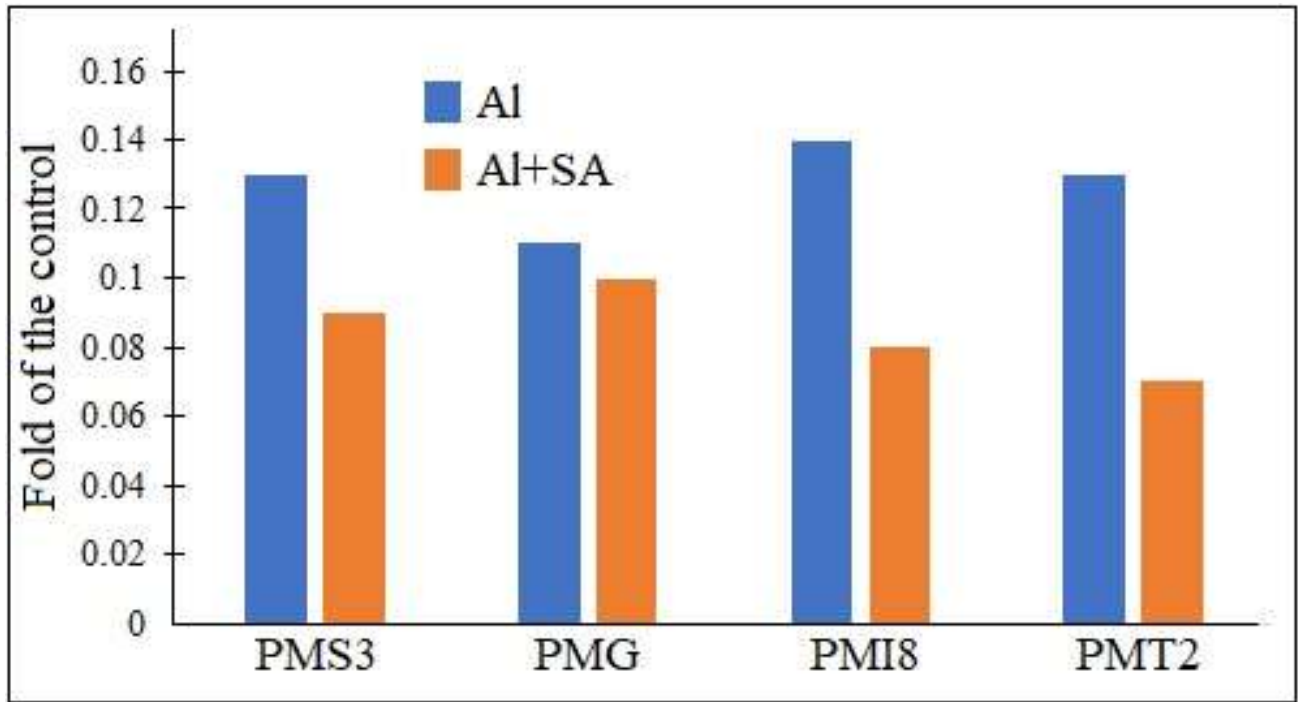

Figure 3:-Global cytosine DNA methylation changes after Al and SA treatments. Aluminum increased the methylation level while SA had reverse effects. Al: aluminum, SA: salicylic acid. 


\section{Epigenetic diversity:-}

The epigenetic diversity induced by aluminum and salicylic acid treatments was determined with Nei epigenetic distance using GenAlex version 5.3. The results showed the Nei epigenetic distance rate was lower between the control $(0 \mathrm{mM}$ aluminum) and treated $(400 \mu \mathrm{M}$ aluminum) plants. In contrast, the application of salicylic acid $(0.5 \mathrm{mM})$ increased the epigenetic variation in all varieties (Figure 4$)$.

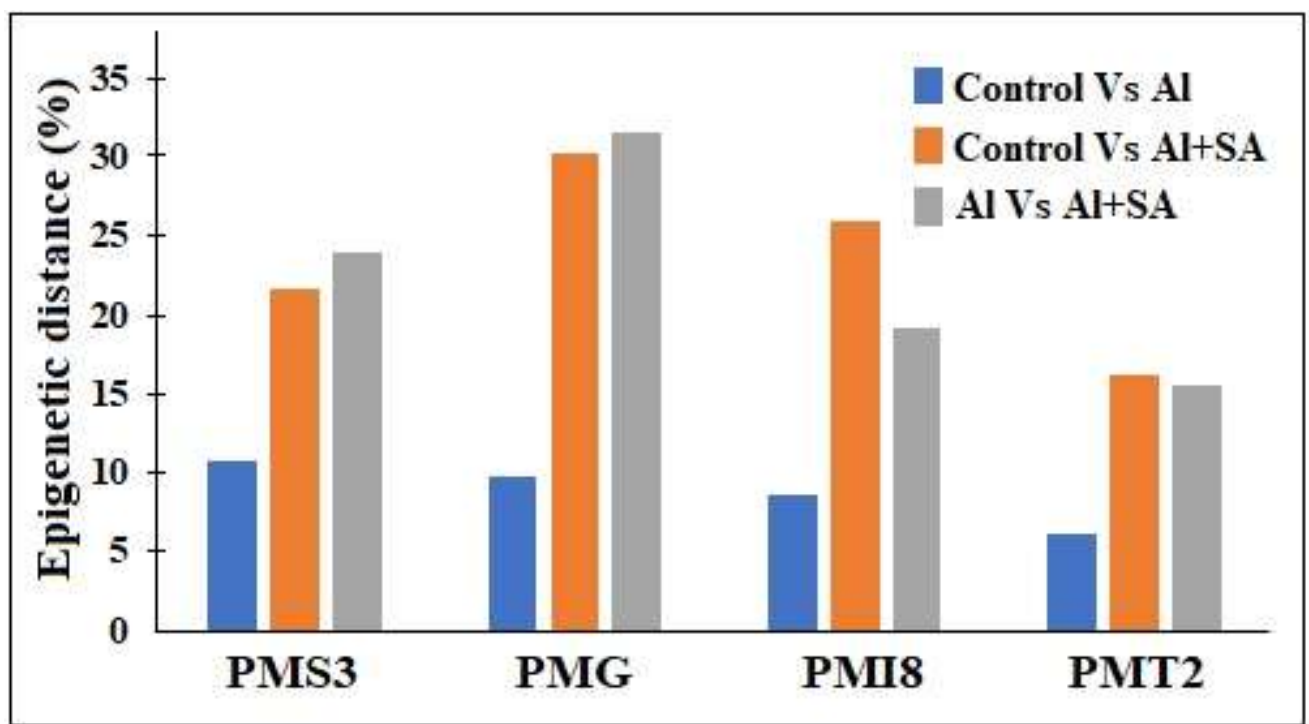

Figure:- Nei epigenetic distance following aluminum stress and application of salicylic acid. Salicylic acid increases the epigenetic variation

\section{Discussion:-}

The effects of aluminum toxicity on epigenome were carried out on four pearl millet varieties. The results revealed a significant difference $(\mathrm{P}<0.05)$ between the controls (without stress) and the plants treated with aluminum and salicylic acid. Indeed, aluminum stress increased the DNA methylation level. Many studies reported similar results in maize (Kimatu et al., 2013; Taspinar et al., 2018) whereas Bednarek et al., (2017) reported contradictory results in Triticale with demethylation occurred during aluminum treatments in CG context.

The application of salicylic acid decreased the genomic methylation level, even though there was genotypedependence. It seems that salicylic acid plays important role in the pearl millet tolerance to aluminum toxicity through demethylation pathway. Plants usually use two mechanisms to tolerate aluminum exposure. Some exclude aluminum from the root apex and others accumulate them in the root and shoot symplasm (Panda et al., 2009). Moreover, many studies revealed the strong evidence of aluminum tolerant genotypes of wheat, corn, sunflower, soybean and common bean excluding aluminum from root by exertion of organic acids that chelate aluminum (López-Bucio et al., 2000; Watanabe \& Osaki, 2002). However, recent studies showed improvement of aluminum tolerance by salicylic acid through the modulation of the reactive oxygen species (Liu et al., 2017). This is accompanied by higher activities of superoxide dismutase, peroxidase, and ascorbate peroxidase, and lower catalase activity, indicating alleviation of aluminum toxicity.

During both aluminum and salicylic acid treatments, the external cytosine methylation varied more compared to the internal cytosine methylation. The external cytosine methylation (hemimethylation) was higher during aluminum, indicating a functional role of the external cytosine. This high occurrence of the hemimethylation during stress could reveal important role of the external cytosine in plant tolerance. In contrast to aluminum, external cytosine demethylation occurred after salicylic acid application, therefore confirming its importance. It could be a key player for identification of de novo methylation events, following changes in the environment or threats. This hemimethylation is very unstable and mainly due to external cues (aluminum and salicylic acid) affecting the methylome pattern. However, the cellular external cytosine DNA methylation and demethylation is far from being explained. Aluminum and salicylic acid could influence the expression of the DOMAINS REARRANGED METHYLTRANSFERASE 2 and DEMETER or Repressor of Silencing 1, respectively. 
Furthermore, the Nei genetic analysis revealed an increase of epigenetic distance following salicylic acid and aluminum treatment. This was more noticed in aluminum and salicylic acid combination than aluminum alone. In fact, the diversity of the epigenetic loci seems to be lowered during stress and normal times in all pearl millet varieties. The epigenetic variation is a mechanism of defense and salicylic acid could confer to the plants more diversity by generating epialleles based-stress. This is used today for crop improvement (Zhang \& Hsieh, 2013), plant biomass increases and stability in ecosystem (Latzel et al., 2013).

This finding revealed the importance of salicylic acid in plant defense, especially on the methylome variation during stress. This research showed that the key player regulating that variation could be the external cytosine of the CCGG motifs.

\section{References:-}

1. AL-Lawati, A., Al-Bahry, S., Victor, R., \& Yaish, M. W. (2016). Salt stress alters DNA methylation levels in alfalfa (Medicago spp), 15(1): 1-16.

2. Bednarek, P. T., Orłowska, R., \& Niedziela, A. (2017). A relative quantitative Methylation-Sensitive Amplified Polymorphism (MSAP) method for the analysis of abiotic stress. BMC Plant Biology, 17(1): 79. https://doi.org/10.1186/s12870-017-1028-0

3. Bennet, R. J., \& Breen, C. (1991). The aluminium signal: new dimensions to the mechanism of aluminium tolerance. Plant Soil, 134: 153-166.

4. Budikova, S., \& Durcekova, K. (2004). Aluminium accumulation in roots of Al-sensitive barley cultivar changes root cell structure and induces callose synthesis. Biologia, 59: 215-220.

5. Chen, Q., Guo, C.-L., Wang, P., Chen, X.-Q., Wu, K.-H., Li, K.-Z., ... Chen, L.-M. (2013). Up-regulation and interaction of the plasma membrane H+-ATPase and the 14-3-3 protein are involved in the regulation of citrate exudation from the broad bean (Vicia faba L.) under Al stress. Plant Physiology and Biochemistry, 70: 504511. https://doi.org/10.1016/j.plaphy.2013.06.015

6. Guo, C. L., Chen, Q., Zhao, X. L., Chen, X. Q., Zhao, Y., \& Wang, L. (2013). Al-enhanced expression and interaction of 14-3-3 protein and plasma membrane H+-ATPase is related to Al-induced citrate secretion in an Al-resistant black soybean. Plant Mol. Biol. Rep, 31: 1012-1024.

7. Kimatu, J. N., Jiang, L., Ngezahayo, F., Songdi, C., Quan-Yuan, Y., Pang, J., \& Liu, B. (2013). Alteration in cytosine DNA methylation patterns and levels induced by aluminium toxicity stress in maize varieties. International Journal of Modern Agriculture International Journal of Modern Agriculture International Journal of Modern Agriculture, 2(21). Retrieved from http://ens.bi/wp-content/uploads/2017/11/Aluminiumtoxicity-in-maize.pdf

8. Kopittke, P. M., Moore, K. L., Lombi, E., Gianoncelli, A., Ferguson, B. J., Blamey, F. P. C., ... Tollenaere, A. (2015). Identification of the Primary Lesion of Toxic Aluminum in Plant Roots. Plant Physiology, 167(4): 1402-1411. https://doi.org/10.1104/pp.114.253229

9. Latzel, V., Allan, E., Bortolini Silveira, A., Colot, V., Fischer, M., \& Bossdorf, O. (2013). Epigenetic diversity increases the productivity and stability of plant populations. Nature Communications, 4: 2875. https://doi.org/10.1038/ncomms3875

10. Liu, N., Song, F., Zhu, X., You, J., Yang, Z., \& Li, X. (2017). Salicylic Acid Alleviates Aluminum Toxicity in Soybean Roots through Modulation of Reactive Oxygen Species Metabolism. Frontiers in Chemistry, 5: 96. https://doi.org/10.3389/fchem.2017.00096

11. López-Bucio, J., Nieto-Jacobo, M. F., Ramírez-Rodríguez, V., \& Herrera-Estrella, L. (2000). Organic acid metabolism in plants: from adaptive physiology to transgenic varieties for cultivation in extreme soils. Plant Science: An International Journal of Experimental Plant Biology, 160(1): 1-13. Retrieved from http://www.ncbi.nlm.nih.gov/pubmed/11164572

12. Ngom, B., Sarr, I., Kimatu, J., Mamati, E., \& Kane, N. A. (2017). Genome-wide analysis of cytosine DNA methylation revealed salicylic acid promotes defense pathways over seedling development in pearl millet. Plant Signaling \& Behavior, 12(9): e1356967. https://doi.org/10.1080/15592324.2017.1356967

13. Panda, S. K., Baluska, F., \& Matsumoto, H. (2009). Aluminum stress signaling in plants. Plant signaling \& behavior, 4(7): 592-597.

14. Peakall, R., \& Smouse, P. E. (2012). GenAlEx 6.5: genetic analysis in Excel. Population genetic software for teaching and research - an update. Bioinformatics, 28: 2537-2539.

15. Pérez-Figueroa, A. (2013). msap: a tool for the statistical analysis of methylation-sensitive amplified polymorphism data. Molecular Ecology Resources, 13(3): 522-527. https://doi.org/10.1111/1755-0998.12064

16. Rengel, Z., \& Zhang, W. H. (2003). Role of dynamics of intracellular calcium in aluminum toxicity syndrome. 
New Phytologist, 159: 295-314.

17. Ryan, P. R., Ditomaso, J. M., \& Kochian, L. V. (1993). Aluminum toxicity in roots: an investigation of special sensitivity and the role of the root cap. J Exp Bot, 44: 437-446.

18. Sade, H., Meriga, B., Surapu, V., Gadi, J., Sunita, M. S. L., Suravajhala, P., \& Kavi Kishor, P. B. (2016). Toxicity and tolerance of aluminum in plants: tailoring plants to suit to acid soils. BioMetals, 29(2): 187-210. https://doi.org/10.1007/s10534-016-9910-z

19. Schmohl, N., \& Horst, W. J. (2000). Cell wall pectin content modulates aluminium sensitivity of Zea mays (L.). Plant, Cell and Environment, 23: 735-742.

20. Shen, H., He, L. F., Sasaki, T., Yamamoto, Y., Zheng, S. J., Ligaba, A., ... Matsumoto, H. (2005). Citrate Secretion Coupled with the Modulation of Soybean Root Tip under Aluminum Stress. Up-Regulation of Transcription, Translation, and Threonine-Oriented Phosphorylation of Plasma Membrane H+-ATPase. PLANT PHYSIOLOGY, 138(1): 287-296. https://doi.org/10.1104/pp.104.058065

21. Takahashi, K., Hayashi, K. -i., \& Kinoshita, T. (2012). Auxin Activates the Plasma Membrane H+-ATPase by Phosphorylation during Hypocotyl Elongation in Arabidopsis. PLANT PHYSIOLOGY, 159(2): 632-641. https://doi.org/10.1104/pp.112.196428

22. Taspinar, M. S., Aydin, M., Sigmaz, B., Yagci, S., Arslan, E., \& Agar, G. (2018). Aluminum-Induced Changes on DNA Damage, DNA Methylation and LTR Retrotransposon Polymorphism in Maize. Arabian Journal for Science and Engineering, 43(1): 123-131. https://doi.org/10.1007/s13369-017-2697-6

23. Watanabe, T., \& Osaki, M. (2002). Mechanisms of adaptation to high aluminum condition in native plant species growing in acid soils: A review. Commun Soil Sci Plant Anal, 33: 1247-1260.

24. Zhang, C., \& Hsieh, T.-F. (2013). Heritable Epigenetic Variation and its Potential Applications for Crop Improvement. Plant Breeding and Biotechnology, 1(4): 307-319. https://doi.org/10.9787/PBB.2013.1.4.307

25. Zhang, J., Wei, J., Li, D., Kong, X., Rengel, Z., Chen, L., ... Chen, Q. (2017). The Role of the Plasma Membrane H+-ATPase in Plant Responses to Aluminum Toxicity. Frontiers in Plant Science, 8: 1757. https://doi.org/10.3389/fpls.2017.01757

26. Zheng, S. J., \& Yang, J. L. (2005). Target sites of aluminum phytotoxicity. Biol. Plant, 49: 321-331. 